\title{
Trends and Differentials in California Fertility Rates 1970-2000
}

\author{
Clark A. Davis and J. Joshua Brown \\ California State University, Chico
}

\begin{abstract}
In this article we examined fertility trends in the State of California from 1970 to 2000. During this period, the population of California increased 69.0 percent, while the percentage of females in the prime reproductive years (15-44) increased 76.5 percent. The number of live births increased from 362,652 in 1970 to a high of 611,666 in 1990 and stood at 531,285 in 2000. There were significant shifts in agespecific fertility rates during the 30 -year period. Live births per 1,000 females declined in age categories $15-19,20-24$ and 25-29 and increased in age categories 30-34, 35-39 and 40-44, suggesting the postponement of child bearing until the later portion of the reproductive cycle. With the exception of 1970 and 1971, total fertility rates were below replacement level fertility through 1986 . From 1987 to 2000, they exceeded replacement level fertility, suggesting fertility has returned as a prime factor in the growth of California's population. With shifting fertility patterns and a diverse racial/ethnic population, the need for education and prenatal care remain as significant policy issues.
\end{abstract}

(C) 2003 Californian Health Promotion Journal. All rights reserved.

Keywords: California, fertility, trends, women

\section{Introduction}

Fertility, actual human reproduction, is a complex dynamic behavior, which is influenced by biological, social and economic conditions. It involves the interplay between intercourse, conception and gestation (Davis \& Blake, 1956). It impacts population composition, age and sex structures and population distributions. Furthermore, behaviors and issues associated with fertility and human reproduction impinge directly or indirectly on a host of relevant and current social issues and draws interest from the scientific community (both biological and social scientists), the medical community, philosophers, ethicist, planners, the religious community and the general public. Although human reproduction is an individual act, the sum of all individual reproduction decisions constitute the fertility trend for the broader social order.

Because of its vast influence, it is not surprising that fertility trends and differentials are monitored and analyzed at local, state, regional, national, international and global levels. California, because of its unique position among the states in the United States - the largest state in the union according to the 2000 Census (U.S. Census, 2000c), the fifth largest economy in the world (State of California, 2000) and its diverse ethnic composition (U.S. Census, 2002) provides an excellent laboratory for the observation of trends and differentials in fertility rates. The purpose of this study is to analyze trends and differentials in fertility rates in the State of California from 1970 to 2000.

\section{Methods of the Study}

Data for this study were obtained from the Vital Statistics Section, Department of Health Services, Center for Health Statistics, State of California Web site (State of California, 2001). It should be noted that live births under age 15 were combined with the 15-19 age category and those live births over age 44 were recorded in the 40-44 age category, which slightly increased the fertility rates and percentages in these two age categories (State of California, 2002).

The measures of fertility that were utilized in this study were: the general fertility rate, agespecific fertility rates and the total fertility rate. 
The general fertility rate is calculated by summing the number of live births for women aged 15-44, divided by the midyear population of women aged 15-44, multiplied by 1,000. The formula for the general fertility rate is:

$$
\text { GFR }=\frac{\text { Total number of live births to women aged } 15-44}{\text { Midyear population of women aged 15-44 }} \times 1,000
$$

Age-specific fertility rates, the best overall measure of fertility, are calculated by dividing the number of live births for women aged $\mathrm{x}$ to $\mathrm{x}$ +5 (women are generally grouped into 5-year age intervals) by the midyear population of women aged $\mathrm{x}$ to $\mathrm{x}+5$, multiplied by a constant of 1,000. The formula for the age-specific fertility rate is:

$$
\text { ASFR }=\frac{\text { Number of live births to women aged } \times \text { to } \times+5}{\text { Midyear population of women aged } \times \text { to } \times+5} \times 1,000
$$

From the data provided by the State of California, total fertility rates, the best crosssectional measure of fertility, were calculated by summing the age-specific fertility rates for each 5 -year age interval ( $x$ to $x+5)$, multiplying the result by 5 , the length of the class interval, and dividing the result by 1,000 , which expresses the total fertility rates in terms of rates per woman, or $\mathrm{k}=1$. In other words with $\mathrm{k}=1$, the total fertility rate is a synthetic measure of fertility. It represents the average number of children a hypothetical woman would bear if she passed through the reproductive years of 15-44 with no mortality, exposed to the same age-specific fertility rates as the women during the year for which the age-specific fertility rates were calculated. The formula for the total fertility rate is:

$$
\mathrm{TFR}=\frac{(\text { Sum ASF }) 5}{1,000}
$$

\section{Analysis of the Data \\ Growth in California's Population}

Before analyzing the trends and differentials in California's fertility rates, it is important to note the changes that have occurred in the state's population from 1970 to 2000 (see Table 1). The midyear population of California in 1970 was $19,953,134$, which increased each decade and stood at $33,871,648$ in 2000 , or an increase of 69.8 percent (see Figure 1).

Table 1

California's Population, 1970-2000

$\begin{array}{cc}\text { Year } & \text { Population } \\ 1970 & 19,953,134 \\ 1980 & 23,667,902 \\ 1990 & 29,760,021 \\ 2000 & 33,871,648\end{array}$

Source: Adapted from the U.S. Census, Census of Population: 1970 and 1980. U.S. Census Bureau, American FactFinder Web site: Age and Sex for the Total Population: 1990. (QT-P1A). U.S. Census Bureau, American FactFinder Web site: Age Groups and Sex: 2000a. (QT-P1). 


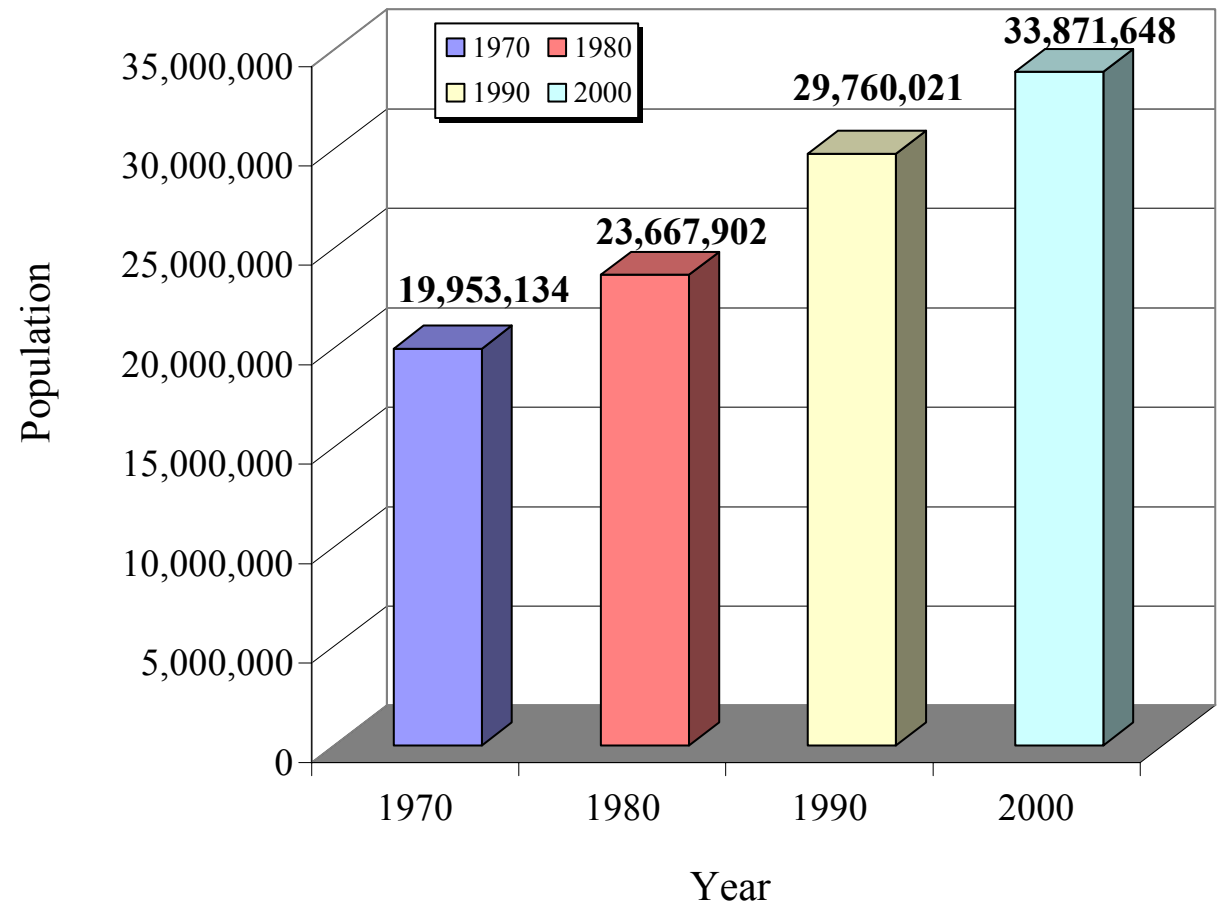

Figure 1

California's Population, 1970-2000

Source: Adapted from the U.S. Census, Census of Population: 1970 and 1980. U.S. Census Bureau, American FactFinder Web site: Age and Sex for the Total Population: 1990. (QT-P1A). U.S. Census Bureau, American FactFinder Web site: Age Groups and Sex: 2000a. (QT-P1).

Similarly, the number of females in the prime reproductive years of 15-44 also increased during the 30 -year period from $4,284,995$ to $7,563,129$, or a 76.5 percent increase. Thus we see that the number of females in the prime reproductive years increased more rapidly than the total population -76.5 to 69.8 percent or a 6.7 percentage point difference (see Table 2). 
Table 2

Number of Women in the Reproductive Years (15-44) in the State of California, 1970-2000

\begin{tabular}{|r|r|r|r|r|r|r|r|}
\hline \multicolumn{7}{|c|}{ Age Categories } & Totals \\
\hline Year & \multicolumn{1}{|c|}{ Age 15-19 } & \multicolumn{1}{|c|}{ Age 20-24 } & Age 25-29 & Age 30-34 & Age 35-39 & \multicolumn{1}{|c|}{ Age 40-44 } & \\
\hline & & & & & & & \\
\hline $\mathbf{1 9 7 0}$ & 886,495 & 868,710 & 730,640 & 608,157 & 574,773 & 616,220 & $4,284,995$ \\
\hline $\mathbf{1 9 8 0}$ & $1,038,781$ & $1,142,897$ & $1,100,153$ & $1,001,445$ & 775,899 & 633,042 & $5,692,217$ \\
\hline $\mathbf{1 9 9 0}$ & 975,466 & $1,161,986$ & $1,359,365$ & $1,377,244$ & $1,233,244$ & $1,066,956$ & $7,174,261$ \\
\hline $\mathbf{2 0 0 0}$ & $1,179,262$ & $1,135,758$ & $1,232,096$ & $1,303,166$ & $1,384,450$ & $1,328,397$ & $7,563,129$ \\
\hline
\end{tabular}

Source: Adapted from the U.S. Census, Census of Population: 1970 and 1980. U.S. Census Bureau, American FactFinder Web site: Age and Sex for the Total Population: 1990. (QT-P1A). U.S. Census Bureau, American FactFinder Web site: Age Groups and Sex: 2000a. (QT-P1).

There were also interesting changes noted in the age distribution of the women in the prime reproductive years from 1970 to 2000 (see Figure 2). Noting the differences between the number of females in 1970 and 2000, there was an increase in the number of females in each 5- year age category. In 1970, the largest number of females were age categories 15-19, 20-24, and 25-29 respectively. However, in the year 2000 the largest number of females were in age categories, 35-39, 40-44 and 30-34 respectively.

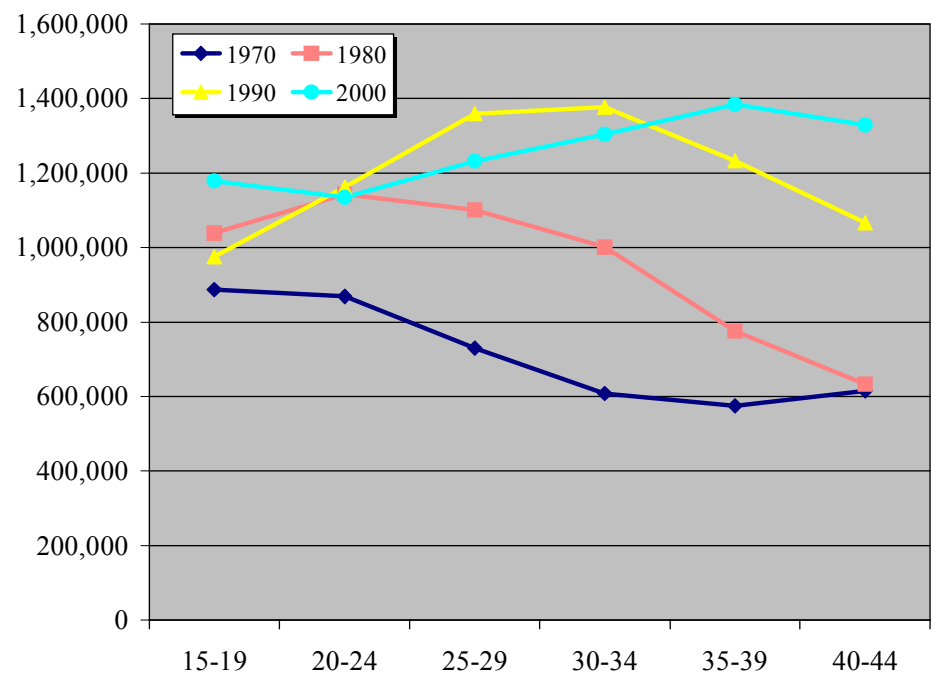

Figure 2

Number of Women in the Reproductive Years (15-44) in the State of California, 1970-2000 Source: Adapted from the U.S. Census, Census of Population: 1970 and 1980. U.S. Census Bureau, American FactFinder Web site: Age and Sex for the Total Population: 1990. (QT-P1A). U.S. Census Bureau, American FactFinder Web site: Age Groups and Sex: 2000a. (QT-P1). 
The percent changes in the respective age categories from 1970 to 2000 also showed interesting differences. The percent increase in age categories 15-19, 20-24 and 25-29 were 33.0, 30.7 and 68.6 percent respectively. All three age categories were below the percentage increase for all women aged 15-44 during the 30-year period, which was 76.5 percent. Conversely, the age categories 30-34, 35-39 and 40-44 increased by $114.3,140.9$ and 115.6 percent respectively. Again illustrating the shift in the composition of women in the prime reproductive years of 15-44 during the 30-year period.

\section{Number of Live Births}

The actual number of live births, the absolute number of reproductive events, provides the raw materials for demographic analysis. During the 30 -years under consideration (1970-2000), there were 14,192,592 live births in the State of California (see Table 3 ). The yearly number of live births fluctuated, sometimes rather drastically, with a high of 611,666 in 1990 and a low of 297,834 in 1973 , illustrating the dynamic nature of reproductive performance.

Table 3

Number of Live Births in the State of California, 1970-2000

\begin{tabular}{|c|c|c|c|}
\hline Year & Live Births & Year & Live Births \\
\hline 1970 & 362,652 & 1986 & 481,905 \\
\hline 1971 & 329,826 & 1987 & 503,376 \\
\hline 1972 & 306,375 & 1988 & 532,708 \\
\hline 1973 & 297,834 & 1989 & 569,308 \\
\hline 1974 & 311,668 & 1990 & 611,666 \\
\hline 1975 & 317,318 & 1991 & 609,228 \\
\hline 1976 & 332,105 & 1992 & 600,838 \\
\hline 1977 & 347,573 & 1993 & 584,483 \\
\hline 1978 & 356,156 & 1994 & 567,034 \\
\hline 1979 & 379,187 & 1995 & 551,226 \\
\hline 1980 & 402,720 & 1996 & 538,628 \\
\hline 1981 & 420,418 & 1997 & 524,174 \\
\hline 1982 & 429,631 & 1998 & 521,265 \\
\hline 1983 & 435,722 & 1999 & 518,073 \\
\hline 1984 & 447,394 & 2000 & 531,285 \\
\hline 1985 & 470,816 & Total & $14,192,592$ \\
\hline
\end{tabular}

Source: Adapted from State of California, Historical Births through 2000, Vital Statistics Section, Department of Health Services, Center for Health Statistics, http://www.dof.ca.gov/html/demograp/report01.xls

A closer examination of the data revealed three general patterns. First, from 1970 to 1973 there was a rather steady decline in the number of live births - declining from 362,652 to 297,834 or a 17.9 percent decline. Second, during the 17year period from 1973 to 1990 , the number of live births incrementally increased from 297,834 to 611,666 , or a 105.4 percent increase.

Third, from 1990 to 1999 there was a decline in the number of live births, declining from 611,666 to 518,073 , or a 15.3 percent decline 
during this 10-year period. However, the number of live births again increased from 1999 to $2000-518,073$ to 531,285 respectively.

\section{General Fertility Rates}

The general fertility rate, as the name implies, gives us a general overview of live births per 1,000 women aged 15-44. During the 30-year period, 1970-2000, the measure fluctuated from a high of 84.7 in 1990 to a low 64.1 in 1973 (see Table 4).

Table 4

General Fertility Rates in the State of California, 1970-2000

\begin{tabular}{|c|r|r|r|}
\hline Year & $\begin{array}{c}\text { General } \\
\text { Fertility Rate }\end{array}$ & Year & $\begin{array}{c}\text { General } \\
\text { Fertility Rate }\end{array}$ \\
\hline 1970 & 84.0 & 1986 & 72.7 \\
\hline 1971 & 74.6 & 1987 & 74.2 \\
\hline 1972 & 67.7 & 1988 & 76.9 \\
\hline 1973 & 64.1 & 1989 & 80.4 \\
\hline 1974 & 65.3 & 1990 & 84.7 \\
\hline 1975 & 64.5 & 1991 & 83.5 \\
\hline 1976 & 65.5 & 1992 & 82.0 \\
\hline 1977 & 66.5 & 1993 & 80.1 \\
\hline 1978 & 65.9 & 1994 & 78.1 \\
\hline 1979 & 68.2 & 1995 & 76.3 \\
\hline 1980 & 70.4 & 1996 & 74.7 \\
\hline 1981 & 71.7 & 1997 & 72.2 \\
\hline 1982 & 71.5 & 1998 & 70.4 \\
\hline 1983 & 70.8 & 1999 & 72.0 \\
\hline 1984 & 71.1 & 2000 & \\
\hline 1985 & 73.0 & & \\
\hline
\end{tabular}

Source: Adapted from State of California, Historical Births through 2000, Vital Statistics Section, Department of Health Services, Center for Health Statistics, http://www.dof.ca.gov/html/demograp/report01.xls

Interesting trends were noted by decades (see Figure 3). Generally speaking, from 1970 to 1979 the general fertility rates, although fluctuating somewhat, remained in the mid- sixties in seven of the ten years, 1972-1978. The decade started with a rate of 84.0 , dipped to 64.1 in 1973 and ended the decade with a rate of 68.2 in 1979. 


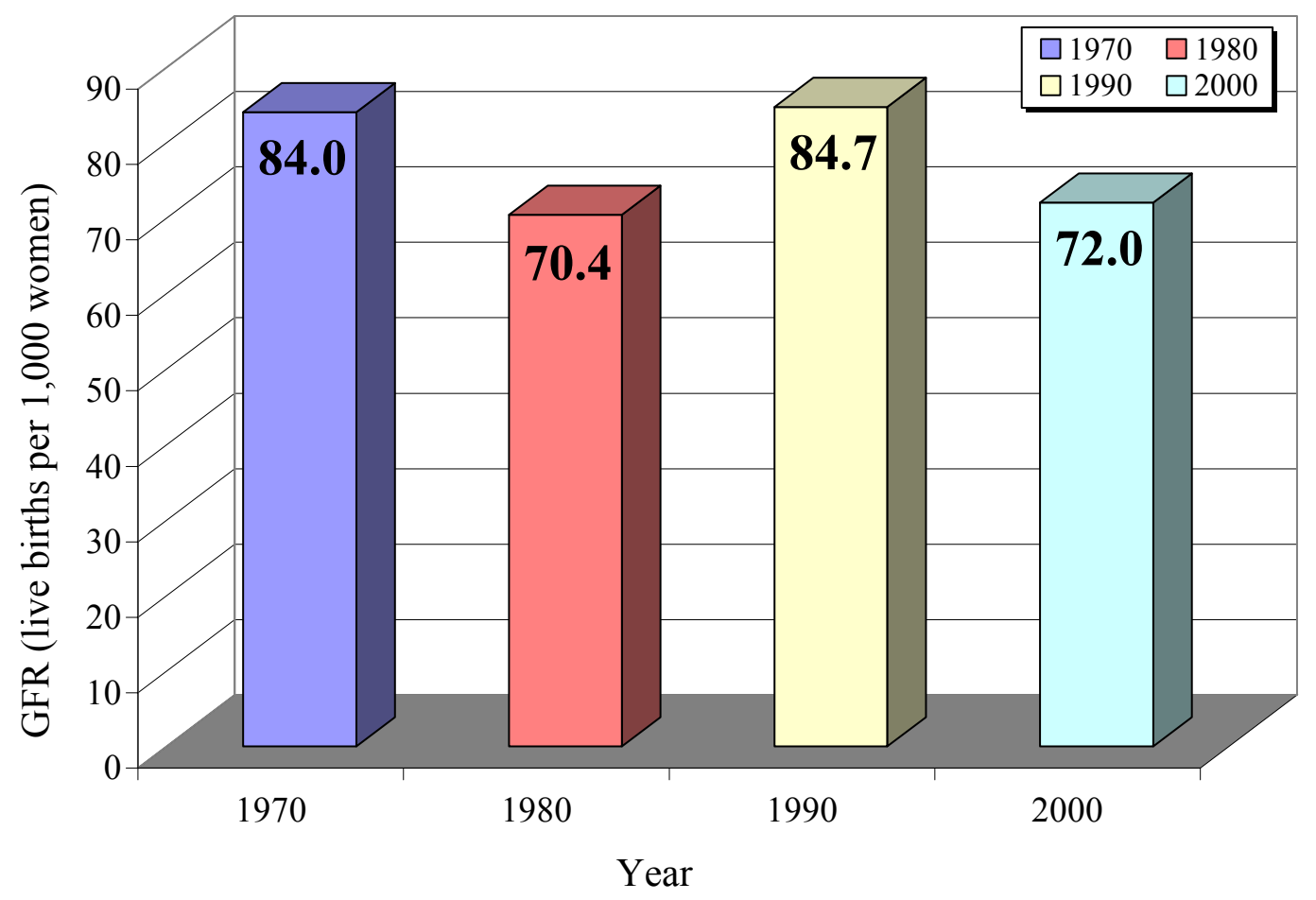

Figure 3

General Fertility Rates in the State of California, 1970-2000

Source: Adapted from State of California, Historical Births through 2000, Vital Statistics Section, Department of Health Services, Center for Health Statistics, http://www.dof.ca.gov/html/demograp/report01.xls

In the decade of the 1980 s, the general fertility rates remained in the low 70 s for seven out of the ten years, 1980-1986. Then increased from 74.2 in 1987 to 80.4 in 1989 . From a high of 84.7 in 1990, the rate steadily declined to a low of 70.5 in 1999 and rose slightly to 72.0 in 2000.

In summary, for the most part, the general fertility rate remained in the mid-sixties in the 1970 s, in the low 70 s in the 1980 s, and declined from the mid-eighties to the low $70 \mathrm{~s}$ in the 1990s.

\section{Percentage of Birth by the Age of Mother}

Analyzing the data by age of the mother as a percentage of all live births illustrated interesting trends over the 30-year period (see Table 5). It is clear that the majority of live births occurred in two age categories-age categories 20-24 and 25-29, generally considered the prime reproductive years. An analysis of these two age categories reveal interesting changes that occurred from 1970 to 2000. Age category 20-24 had a higher percentage of the total live births than age 
category 25-29 (or any other age category) from 1970 to 1982 - declining from 37.9 percent in 1970 to 31.7 percent in 1982-while age category 25-29 had a higher percentage of live births from 1983 to 2000 - declining from 31.5 percent in 1983 to 26.3 percent in 2000 .

Combining the percentage of live births in age categories 20-24 and 25-29 for the 30-year period (1970-2000) shows dramatic changes in the contribution of these two prime reproductive age categories to the total percentage of all live births. In 1970, women aged 20-29 accounted for 65.2 percent of all live births, which increased to 65.8 percent in 1971. From 1971, the percent contribution of the 20-29 age category steadily decreased from the 65.8 high to a low of 49.4 percent in 2000 . Thus, from 1970 to 2000 there was a 15.8 percentage point difference or a 24.2 percent decline in the percentage contribution of this age category to the percentage of all live births.

Although the percentage contribution of the 2029 age category declined in their contribution to the percentage of all live births during the 30year period, the total number of live births increased from 236,305 in 1970 to 262,259 in 2000 , or an increase of 11.0 percent (State of California, 2001). However, at the same time there was an increase in the number of women in these two age categories, increasing from $1,599,350$ in 1970 to $2,367,854$ in 2000 or an increase of 48.1 percent.

Table 5

Percentage of Live Births by Age in the State of California, 1970-2000

\begin{tabular}{|r|c|c|c|c|c|r|r|}
\hline \multicolumn{7}{|c|}{ Age and Percent of Live Births } & $\begin{array}{c}\text { Total } \\
\text { Percent }\end{array}$ \\
\hline Year & Age 15-19 & Age 20-24 & Age 25-29 & Age 30-34 & Age 35-39 & Age 40-44 & \\
\hline & $(\%)$ & $(\%)$ & $(\%)$ & $(\%)$ & $(\%)$ & $(\%)$ & 100.1 \\
\hline 1970 & 17.0 & 37.9 & 27.3 & 11.9 & 4.7 & 1.3 & 1.3 \\
\hline 1971 & 16.5 & 38.0 & 27.8 & 12.0 & 4.5 & 1.5 & 99.9 \\
\hline 1972 & 17.3 & 36.1 & 28.9 & 12.3 & 4.2 & 1.1 & 100.0 \\
\hline 1973 & 17.3 & 35.4 & 29.6 & 12.6 & 4.1 & 1.0 & 99.9 \\
\hline 1974 & 16.9 & 35.0 & 30.2 & 12.9 & 4.0 & 0.9 & 100.0 \\
\hline 1975 & 16.8 & 34.5 & 30.6 & 13.2 & 4.0 & 0.9 & 100.0 \\
\hline 1976 & 16.2 & 34.3 & 30.8 & 13.7 & 4.1 & 0.9 & 100.0 \\
\hline 1977 & 15.5 & 34.3 & 30.5 & 14.7 & 4.1 & 0.9 & 99.9 \\
\hline 1978 & 15.0 & 33.8 & 30.4 & 15.6 & 4.3 & 0.8 & 100.0 \\
\hline 1979 & 14.4 & 33.4 & 30.4 & 16.3 & 4.6 & 0.9 & 100.0 \\
\hline 1980 & 13.8 & 33.2 & 30.5 & 16.8 & 4.8 & 0.9 & 100.0 \\
\hline 1981 & 13.3 & 32.6 & 30.8 & 17.4 & 5.0 & 0.9 & 100.0 \\
\hline 1982 & 12.6 & 31.7 & 31.4 & 17.7 & 5.6 & 1.0 & 100.0 \\
\hline 1983 & 11.8 & 30.8 & 31.5 & 18.7 & 6.2 & 1.0 & 100.0 \\
\hline 1984 & 11.2 & 30.1 & 31.7 & 19.3 & 6.6 & 1.1 & 100.0 \\
\hline 1985 & 10.9 & 29.1 & 31.8 & 20.0 & 7.1 & 1.1 & 99.9 \\
\hline 1986 & 10.9 & 28.1 & 31.6 & 20.5 & 7.6 & 1.2 & 99.9 \\
\hline 1987 & 10.8 & 27.0 & 31.4 & 21.3 & 8.0 & 1.4 & 100.0 \\
\hline 1988 & 11.1 & 26.1 & 31.2 & 21.7 & 8.4 & 1.5 & 100.1 \\
\hline 1989 & 11.4 & 26.0 & 30.7 & 21.6 & 8.7 & 1.7 & 100.0 \\
\hline 1990 & 11.6 & 26.1 & 29.9 & 21.8 & 8.9 & 1.7 & 100.1 \\
\hline 1991 & 11.8 & 26.1 & 29.1 & 21.9 & 9.3 & 1.9 & 100.1 \\
\hline 1992 & 11.8 & 25.8 & 28.5 & 22.2 & 9.8 & 2.0 & 100.0 \\
\hline 1993 & 12.0 & 25.5 & 27.9 & 22.5 & 10.0 & 2.1 & 100.0 \\
\hline 1994 & 12.3 & 24.7 & 27.3 & 22.9 & 10.5 & 2.3 & \\
\hline
\end{tabular}




\begin{tabular}{|r|c|c|c|c|c|r|r|}
\hline \multicolumn{7}{|c|}{ Age and Percent of Live Births } & Total \\
Pear & Age 15-19 & Age 20-24 & Age 25-29 & Age 30-34 & Age 35-39 & Age 40-44 & Aent \\
\hline 1995 & 12.4 & 24.1 & 27.0 & 23.2 & 11.0 & 2.4 & 100.1 \\
\hline 1996 & 12.0 & 23.7 & 27.1 & 23.2 & 11.5 & 2.6 & 100.1 \\
\hline 1997 & 11.7 & 23.5 & 26.9 & 23.3 & 12.0 & 2.7 & 100.1 \\
\hline 1998 & 11.4 & 23.3 & 26.9 & 23.3 & 12.3 & 2.8 & 100.0 \\
\hline 1999 & 11.1 & 23.2 & 26.6 & 23.5 & 12.6 & 2.9 & 99.9 \\
\hline 2000 & 10.6 & 23.1 & 26.3 & 24.0 & 12.9 & 3.1 & 100.0 \\
\hline
\end{tabular}

Source: Adapted from State of California, Historical Births through 2000, Vital Statistics Section, Department of Health Services, Center for Health Statistics, http://www.dof.ca.gov/html/demograp/report01.xls

Shifts in the percentage contribution of the 2024 and the 25-29 age categories to the total percentage of all live births from 1970 to 2000 in the State of California suggest changing patterns in the other age categories. An analysis of the percentage contribution of age category 15-19 to the total percentage of all live births reveals an interesting trend. Women aged 1519 contributed 17.0 percent of all live births in 1970 with their highest percent contribution of 17.3 percent in 1972 and 1973 . With some fluctuations, this age category declined from the high of 17.3 percent in 1972 and 1973 to a low of 10.6 percent in 2000 - a 6.4 percentage point difference or a 37.7 percent decline in the percentage contribution of the 15-19 age category to the total percentage of all live births during the 30 -year period

While age categories 15-19, 20-24 and 25-29 decreased in their percentage contribution to the total percentage of all live births from 1970 to 2000, age category 30-34 incrementally increased from 11.9 percent in 1970 to 24.0 percent in 2000-a 12.1 percentage point difference between the two time periods. This percentage point difference translates into a 101.7 percent increase from 1970 to 2000 .

The percentage contribution of age category 35 39 to the total percentage of all live births declined from 4.7 percent in 1970 to 4.0 percent in 1975. Then, similar to age category 30-34, the percentage contribution of this age category incrementally increased from 4.0 percent in
1975 to 12.9 percent in 2000 . Thus from 1970 to 2000 there was a 174.5 percent increase in the percent contribution of this age category to the total percent of all live births.

Combining the percent contribution of age categories 30-34 and 35-39 to the total percentage of all live births from 1970 to 2000, we note significant changes between the two time periods. From holding rather steady in the percentage of live births in the early 70s, 19701973, the percent contribution of the 30-39 age category increased from 16.6 percent in 1970 to 36.9 in $2000-a$ a 20.3 percentage point difference or a 122.3 percent increase in the contribution to all live births between the two time periods. Indicating the propensity for women to extend their reproduction throughout the 30-39 age category.

As expected, the lowest percentage contribution to the total percentage of all live births from 1970 to 2000 occurred in age category 40-44. They contributed 1.3 percent of the live births in 1970 and around 1.0 percent until 1983. From 1983 the percent contribution of this age category increased from 1.0 to 3.1 percent in 2000. Although the percentage point difference from 1970 to 2000 is only 1.8, the percent contribution of this age category to the percentage of all live births from 1970 to 2000 increased 138.5 percent.

In summary, age categories 15-19, 20-24 and 25-29 decreased in their percentage contribution 
to the total percentage of all live births from 1970 to 2000. Conversely, age categories 3034, 35-39 and 40-44 increased their percentage contribution to the total percentage of all live births.

\section{Age-Specific Fertility Rates}

The total number of live births, the general fertility rate, and the percentage of live births in each age category, in and of themselves, do not tell the whole story relative to reproductive performance. An analysis of the total population of women in the reproductive period of their lives and the ages of women giving birth per 1,000 generate a clearer picture of reproductive performance (see Table 6).

Table 6

Age-Specific Fertility Rates in the State of California, 1970-2000

\begin{tabular}{|r|r|r|r|r|r|r|}
\hline Year & \multicolumn{7}{|c|}{$\begin{array}{c}\text { Age-Specific Fertility Rates } \\
\text { (per 1,000 live births) }\end{array}$} \\
\hline & Age 15-19 & Age 20-24 & Age 25-29 & Age 30-34 & Age 35-39 & Age 40-44 \\
\hline $\mathbf{1 9 7 0}$ & 69.2 & 156.2 & 134.3 & 70.1 & 29.2 & 7.5 \\
\hline $\mathbf{1 9 7 1}$ & 58.5 & 136.4 & 120.9 & 62.8 & 25.5 & 6.8 \\
\hline $\mathbf{1 9 7 2}$ & 55.1 & 119.8 & 109.4 & 57.7 & 22.2 & 5.7 \\
\hline $\mathbf{1 9 7 3}$ & 52.0 & 111.8 & 104.2 & 54.2 & 20.7 & 5.2 \\
\hline $\mathbf{1 9 7 4}$ & 52.0 & 112.4 & 106.4 & 55.6 & 21.0 & 4.9 \\
\hline $\mathbf{1 9 7 5}$ & 51.6 & 109.2 & 104.1 & 55.4 & 20.4 & 5.1 \\
\hline $\mathbf{1 9 7 6}$ & 51.3 & 109.4 & 103.8 & 58.2 & 21.5 & 4.8 \\
\hline $\mathbf{1 9 7 7}$ & 51.2 & 109.8 & 106.0 & 60.6 & 21.6 & 5.0 \\
\hline $\mathbf{1 9 7 8}$ & 50.9 & 107.8 & 104.8 & 62.0 & 21.9 & 4.8 \\
\hline $\mathbf{1 9 7 9}$ & 52.0 & 111.5 & 107.8 & 65.4 & 23.5 & 5.2 \\
\hline $\mathbf{1 9 8 0}$ & 53.2 & 116.2 & 111.4 & 67.4 & 24.7 & 5.3 \\
\hline $\mathbf{1 9 8 1}$ & 53.7 & 117.5 & 114.2 & 69.1 & 26.0 & 5.8 \\
\hline $\mathbf{1 9 8 2}$ & 52.0 & 116.1 & 115.2 & 71.1 & 27.7 & 5.8 \\
\hline $\mathbf{1 9 8 3}$ & 50.0 & 113.0 & 114.7 & 74.4 & 29.3 & 6.0 \\
\hline $\mathbf{1 9 8 4}$ & 49.2 & 111.8 & 116.4 & 77.0 & 30.7 & 6.3 \\
\hline $\mathbf{1 9 8 5}$ & 50.2 & 113.1 & 120.1 & 81.4 & 32.8 & 6.5 \\
\hline $\mathbf{1 9 8 6}$ & 50.9 & 112.5 & 119.1 & 82.6 & 33.8 & 6.9 \\
\hline $\mathbf{1 9 8 7}$ & 52.9 & 112.8 & 121.6 & 86.1 & 36.5 & 7.7 \\
\hline $\mathbf{1 9 8 8}$ & 57.2 & 117.0 & 125.1 & 89.5 & 39.4 & 8.2 \\
\hline $\mathbf{1 9 8 9}$ & 64.1 & 125.0 & 128.9 & 92.0 & 41.8 & 8.9 \\
\hline $\mathbf{1 9 9 0}$ & 71.4 & 135.4 & 133.6 & 96.6 & 44.2 & 9.6 \\
\hline $\mathbf{1 9 9 1}$ & 74.4 & 135.7 & 132.3 & 94.3 & 44.6 & 9.8 \\
\hline $\mathbf{1 9 9 2}$ & 73.3 & 134.8 & 129.0 & 93.8 & 44.5 & 10.2 \\
\hline $\mathbf{1 9 9 3}$ & 72.9 & 132.8 & 127.6 & 92.4 & 43.5 & 10.3 \\
\hline $\mathbf{1 9 9 4}$ & 72.0 & 130.0 & 125.4 & 91.9 & 43.5 & 10.7 \\
\hline $\mathbf{1 9 9 5}$ & 68.9 & 128.2 & 124.0 & 91.9 & 43.7 & 10.8 \\
\hline $\mathbf{1 9 9 6}$ & 63.1 & 128.1 & 123.7 & 92.7 & 44.0 & 11.0 \\
\hline $\mathbf{1 9 9 7}$ & 57.9 & 122.8 & 121.7 & 91.5 & 44.5 & 11.0 \\
\hline $\mathbf{1 9 9 8}$ & 54.2 & 120.3 & 122.3 & 93.5 & 45.2 & 11.1 \\
\hline $\mathbf{1 9 9 9}$ & 51.2 & 116.4 & 122.5 & 95.8 & 46.0 & 11.1 \\
\hline $\mathbf{2 0 0 0}$ & 48.9 & 114.8 & 127.1 & 101.5 & 48.5 & 11.9 \\
\hline & & & & & & \\
\hline
\end{tabular}

Source: Adapted from State of California, Historical Births through 2000, Vital Statistics Section, Department of Health Services, Center for Health Statistics, http://www.dof.ca.gov/html/demograp/report01.xls 
As previously mentioned, age-specific fertility rates are calculated by dividing the number of live births for women aged $\mathrm{x}$ to $\mathrm{x}+5$ by the midyear population of women aged $\mathrm{x}$ to $\mathrm{x}+5$ multiplied by a constant of 1,000 . Patterns similar to, but differing somewhat from those discussed in percentage distribution of live births by age emerges when analyzing agespecific fertility rates.

As in the analysis of percentage of live births by age, the age-specific fertility rates in age categories 20-24 and 25-29 again emerged as the prime reproductive years for women in the State of California from 1970 to 2000 . The highest age-specific fertility rates for both age categories occurred in 1970 with 156.2 and 134.3 live births per thousand women respectively, which combined accounted for 65.2 percent of the live births in 1970 . From 1970 to 1982 and 1990 to 1997 , women in age category 20-24 had the highest age-specific fertility rates of any 5-year age category. Age category 25-29 had the highest age-specific fertility rates from 1983 to 1989 and 1998 to 2000.

For the teen years, age category 15-19, agespecific fertility rates have fluctuated considerably. Rates declined from 1970 to 1978, from 69.2 to 50.9. They increased from 1978 to 1981 and stood at 53.7, decreased through 1984 to 49.2 and increased through 1991 to 74.4 . Since 1991 age-specific fertility rates consistently declined to an all time low for the 30 -year period to 48.9 in 2000.

The 30-34 age category contained the third highest age-specific fertility rates of all age categories from 1970 to 2000 . Rates fluctuated for a high of 70.1 in 1970 to a low of 54.2 in 1973 and finished the decade with 65.4. From 1980 age-specific fertility rates incrementally increased from 67.4 to 92.0 in 1989 or an increase of 24.6 live births per thousand women aged 30-34. During the 1990s age-specific fertility rates in the 30-34 age category fluctuated from the mid to low 90 s and reached an all time high of 101.5 for the 30 -year period in the year 2000.

In other words, to put the 30-34 age category in perspective, since 1980 there has been an increase of 34.1 live births per thousand women aged 30-34.

Age category 35-39 commenced the 30-year period with an age-specific fertility rate of 29.2. Rates declined to a low of 20.4 in 1975 and finished the decade standing at 23.5. Since 1979, age-specific fertility rates have incrementally increased each year, with minor exceptions, from 23.5 in 1979 to 48.5 in 2000 or an increase of 25.0 live births per thousand women aged 35-39. Data from the 30-34 and the 35-39 age categories definitely demonstrates the postponement of fertility into the later years of the reproductive cycle.

The lowest age-specific fertility rates were recorded in age category 40-44. In the decade of the $70 \mathrm{~s}$, the age-specific fertility rates declined from a high of 7.5 in 1970 to a low of 4.8 in 1976 and 1978 and finished the decade at 5.2. Since then age-specific fertility rates have incrementally increased each year, with the exceptions of 1981-82, 1996-97 and 1998-99 where age-specific fertility rates remained constant at 5.8, 11.0 and 11.1 respectively, and then rose to 11.9 in 2000. Although changes in age-specific fertility rates in the 40-44 age category have not been dramatic, the shift has been in the direction of higher rates in this age category.

In summary, over the 30-year period of 19702000 there was a significant decline in agespecific fertility rates for age categories 15-19, 20-24 and 25-29, which declined by $-29.3,-26.5$ and -5.4 percent respectively. Conversely, agespecific fertility rates increased in age 
categories 30-34, 35-39 and 40-44, which increased by $44.8,66.1,58.7$ percent respectively, illustrating the postponement of child bearing into the early and late thirties (see Figure 4).

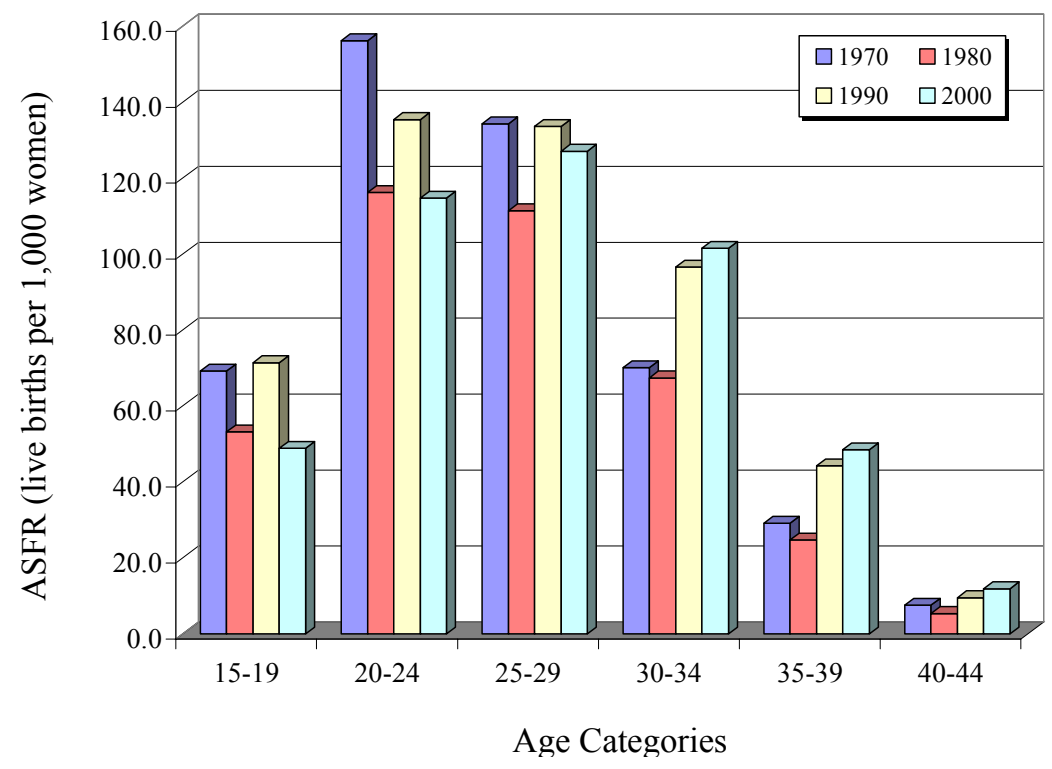

Figure 4

Age-Specific Fertility Rates in the State of California, 1970-2000

Source: Adapted from State of California, Historical Births through 2000, Vital Statistics Section, Department of Health Services, Center for Health Statistics, http://www.dof.ca.gov/html/demograp/report01.xls

\section{Total Fertility Rates}

Another perspective on reproductive performance can be obtained by the calculation of total fertility rates. Again, the total fertility rate is a synthetic measure of fertility representing the average number of children a hypothetical cohort of women would bear if they passed through their reproductive years, with no mortality, and exposed to the same agespecific fertility rates as the women during the year for which the age-specific fertility rates were calculated.

From 1970 to 2000 , the highest total fertility rate, 2.5, occurred in 1990 and 1991 (see Table
7). In other words, for 1990 and 1991 females passing through their reproductive years of 15 44 would have had an average of 2.5 children. Replacement fertility, the average number of children a woman would need to bear to replace the population, is 2.1. Hence, if age-specific fertility rates would have persisted between the respective years of 1970 and 2000, fertility levels high enough to have maintained, or contributed to population growth, would have occurred in 1970-1971 and 1987-2000 (see Figure 5). During the remaining years, fertility levels, had they persisted, would not have been sufficient to maintain the population. 


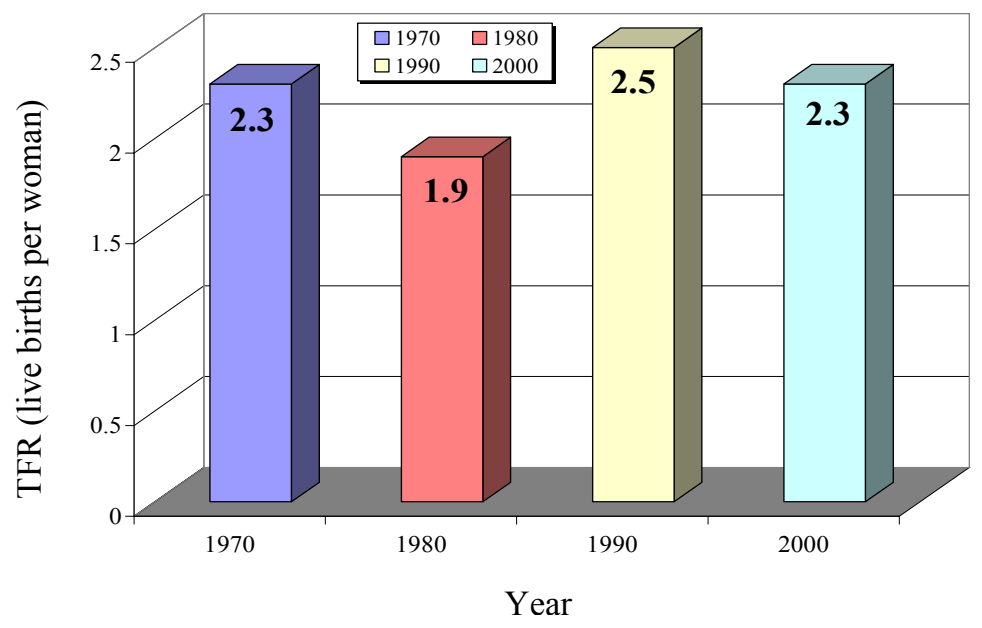

Figure 5

Total Fertility Rates in the State of California, 1970-2000

Source: Adapted from State of California, Historical Births through 2000, Vital Statistics Section, Department of Health Services, Center for Health Statistics, http://www.dof.ca.gov/html/demograp/report01.xls

Table 7

Total Fertility Rates in the State of California, 1970-2000

\begin{tabular}{|c|c|c|c|c|}
\hline Year & $\begin{array}{c}\text { Total } \\
\text { Fertility Rates }\end{array}$ & Year & $\begin{array}{c}\text { Total Fertility } \\
\text { Rates }\end{array}$ \\
\hline 1970 & 2.3 & & 1986 & 2.0 \\
\hline 1971 & 2.1 & & 1987 & 2.1 \\
\hline 1972 & 1.9 & & 1988 & 2.2 \\
\hline 1973 & 1.7 & & 1989 & 2.3 \\
\hline 1974 & 1.8 & & 1990 & 2.5 \\
\hline 1975 & 1.7 & & 1991 & 2.5 \\
\hline 1976 & 1.7 & & 1992 & 2.4 \\
\hline 1977 & 1.8 & & 1993 & 2.4 \\
\hline 1978 & 1.8 & & 1994 & 2.4 \\
\hline 1979 & 1.8 & & 1995 & 2.3 \\
\hline 1980 & 1.9 & & 1996 & 2.3 \\
\hline 1981 & 1.9 & & 1997 & 2.2 \\
\hline 1982 & 1.9 & & 1998 & 2.2 \\
\hline 1983 & 1.9 & & 1999 & 2.2 \\
\hline 1984 & 2.0 & & 2000 & 2.3 \\
\hline 1985 & 2.0 & & & \\
\hline
\end{tabular}

Source: Adapted from State of California, Historical Births through 2000, Vital Statistics Section, Department of Health Services, Center for Health Statistics, http://www.dof.ca.gov/html/demograp/report01.xls 
During the 30-years under consideration, the data on total fertility rates indicate that fertility has been a major contributor to population growth in the State of California, especially since 1987.

\section{Summary and Conclusions}

From 1970 to 2000 the population of California increased from $19,953,134$ to $33,871,648$ an increase of 69.8 percent. During the same period, the number of females in the prime reproductive years (15-44) increased from $4,284,995$ to $7,563,129$, or a 76.5 percent increase. However, there was an uneven increase in the age distribution of the women in the prime reproductive years when broken down into 5-year age intervals. In 1970, the largest number of females were age categories 15-19, 20-24, and 25-29 respectively, while in the year 2000 the largest number of females were in age categories, 35-39, 40-44 and 30-34 respectively.

The percent increase in age categories 15-19, 20-24 and 25-29 were 33.0, 30.7 and 68.6 percent respectively, while the 30-34, 35-39 and 40-44 age categories increased by $114.3,140.9$ and 115.6 percent respectively, illustrating the shift in the composition of women in the prime reproductive years of 15-44 during the 30-year period.

During the 30-years under consideration (19702000) there were $14,192,592$ live births in the State of California. The general fertility rate fluctuated from a high of 84.7 in 1990 to a low 64.1 in 1973. During the bulk of the 1970s the general fertility rate remained in the mid-sixties, in the 1980s it remained in the low 70s, while in the 1990s it declined from a high of 84.7 in 1990 to a low of 70.5 in 1999.

When analyzing the data by age of the mother as a percentage of all live births, the majority of live births occurred in age categories 20-24 and 25-29. However, their contribution declined from 65.2 percent of all live births to a low of 49.4 in 2000 , while the number of women in these two age categories increased 48.1 percent.

While age categories 15-19, 20-24 and 25-29 decreased in their percentage contribution to the total percentage of all live births from 1970 to 2000, age categories 30-34, 35-39 and 40-44 increased their percentage contribution to all live births.

Age-specific fertility rates exhibited patterns similar to the percentage distribution of live births by age of mother. There was a significant decline in age-specific fertility rates for age categories 15-19, 20-24 and 25-29, while agespecific fertility rates increased in age categories 30-34, 35-39 and 40-44 over the 30year period. Although the 20-24 and 25-29 age categories have been the prime reproductive age categories during the past 30-years, their rates have declined, while age-specific fertility in the 30-34 and 35-39 age categories have increased, illustrating the postponement of child bearing into the early and late thirties.

Total fertility rates reached the replacement level, 2.1, in 1970-1971 and 1987-2000. During the remaining years, fertility levels, had they persisted, would not have been high enough to maintain the population through human reproduction.

The reasons for shifting patterns in California's fertility rates are complex. However, two factors emerge as important contributors to the overall pattern. First, the proportion of live births occurring to foreign-born women has been and is an important factor in the dynamics of California fertility patterns. The percent of births to this segment of the population has significantly increased over the past two decades. For example, live births to foreignborn females increased from 30.0 percent in 1982 to approximately 45.0 percent in 1997 (Tafoya, 2000). The largest segment of the foreign-born population in California is Hispanic, largely consisting of those of Mexican 
origin. Foreign-born Hispanic fertility rates exceeded those of females born in the United States both for individuals of Hispanic and nonHispanic origins (Johnson, Hill \& Heim, 2001). Thus the percent of Hispanic foreign-born females, especially those of Mexican origin, in the reproductive years has had an important influence on California's fertility rates.

Second, in conjunction with the foreign-born population is the racial/ethnic composition of the California's population. Hispanics, the largest minority population in the statecomprising approximately 30.0 percent of the population in 2000 - is primarily composed of individuals of Mexican origin-individuals of Mexican origin constituted 77.1 percent of the Hispanic population in the state in 2000 (U.S. Census, 2000b) - who historically have had high fertility rates. From 1999 and 2001, Hispanics accounted for roughly 30.0 percent of the state's population; however they contributed approximately 50.0 percent of the live births during this period. Hispanics, compared to other racial/ethnic groups, had high teenage fertility rates, high age-specific fertility rates and total fertility rates that were well above replacement level fertility and higher than those of other racial/ethnic populations (Davis \& Brown, 2003). Thus, the foreign-born and the racial/ethnic composition of California's population have played and will continue to play significant roles in the growth of the state's population.

\section{Implications}

The public policy issues related to the analysis of California's fertility data are closely allied with the nature and composition of the state's population. California has a diverse racial/ethnic population with differing fertility patterns. Thus, the need to reach out to and provide appropriate information for a significant number of foreign-born individuals and a diverse racial/ethnic population becomes apparent. Education about human reproduction is essential for all segments of California's population, especially for the teenagers. Although teenage birth rates in California have declined, research data suggest that life chances for children born to teenage mothers are adversely affected when compared to those born to older women (Maynard, 1997). With an increasing number of births occurring to teenage mothers who have never been married-78.0 percent of teenage births in California in the year 2000 occurred to teenagers who had never been married (Johnson, 2003) - the need for educational and community programs focused on reproductive issues designed to meet the needs of the diverse racial/ethnic teenage population is apparent.

Research data have demonstrated the unfulfilled need for prenatal care, especially in the first trimester for minority women. In California from 1998 to 2000, a significant number of minority women (20.0 percent of Hispanic and Black women and approximately 27.0 percent for American Indians or Alaska Natives) did not receive medical care in the first trimester of their pregnancies (CDC, 2002). Significant progress has been made in this area but major gaps in prenatal care still exist and need to be addressed.

As stated earlier, fertility, actual human reproduction, is a complex dynamic behavior, which is influenced by biological, social and economic conditions. The changing patterns of fertility in the State of California from 1970 to 2000 illustrate the fluid nature of reproductive performance. Although this study was a descriptive study, the fettering out of the dynamics involved in reproductive choice remains a challenge for demographers. 


\section{References}

Centers for Disease Control and Prevention. (2002). Early prenatal care according to race and Hispanic origin of mother, geographic division, and state: United States, average annual 1992-94, 199597, and 1998-2000. (Table 7). Retrieved March 23, 2003, from http://www.cdc.gov/nchs/data/hus/tables/2002/02hus007.pdf

Davis, C. A., \& Brown, J. J. (2003). Recent trends in California Hispanic fertility rates - a comparative analysis. Californian Journal of Health Promotion, 1(2), 78-87. Retrieved June 1, 2003, from http://www.csuchico.edu/cjhp/1/2/78-87-davis.pdf

Davis, K., \& Blake, J. (1956). Social structure and fertility: An analytic framework. Economics Development and Cultural Change, 4(4), 211-35.

Johnson, H. P. (2003). Maternity before maturity: Teen birth rates in California. California Counts, 4(3), 1-19. Retrieved February 20, 2002, from http://www.ppic.org/content/pubs/CC 203HJCC.pdf

Johnson, H. P., Hill, L., \& Heim, M. (2001). New trends in newborns: Fertility rates and patterns in California. California Counts, 3(1), 1-11. Retrieved February 20, 2002, from http://www.ppic.org/content/pubs/CC 801HJCC.pdf

Maynard, R. A. (Ed.). (1997). Kids having kids: Economic costs and social consequences of teen pregnancy. Washington, DC: Urban Institute Press.

State of California. (2000). California office of trade and investment - Statistics. Retrieved September 22, 2002, from http://www.california.co.za/californiastatistics.htm

State of California. (2001). Actual and projected births by county, 1970-2010, with births by age of mother and fertility rates. Retrieved July 2, 2002, from http://www.dof.ca.gov/html/demograp/report01.xls

State of California. (2002). Historical and projected births by county, 1970-2011, with births by age of mother and fertility rates. Retrieved September 30, 2002, from http://www.dof.ca.gov/HTML/DEMOGRAP/01Births.htm

Tafoya, S. M. (2000). Check one or more... Mixed race and ethnicity in California. California Counts, 1(2). Retrieved May 18, 2003, from http://www.ppic.org/content/pubs/CC 100STCC.pdf

United States Bureau of the Census, Census of Population: 1970, Vol. I, Characteristics of the Population, Part 6, California-Section 1.

United States Bureau of the Census, Census of Population: 1980, Vol. I, Characteristics of the Population, Part 6, California.

United States Census Bureau. (1990). Age and Sex for the Total Population: 1990. (Publication No. QTP1A). Retrieved September 29, 2002, from http://factfinder.census.gov/servlet/DatasetTableListServlet?_ds_name=DEC_1990_STF1_\& ty $\mathrm{pe}=$ table \& lang $=$ en \& program $=$ DEC \& ts $=53842410319$

United States Census Bureau. (2000a). Age Groups and Sex: 2000. (Publication No. QT-P1). Retrieved September 29, 2002, from http://factfinder.census.gov/servlet/DatasetTableListServlet? ds name=DEC 2000 SF1 U\& ty pe $=$ table \& lang $=$ en \& program $=$ DEC $\&$ ts $=53840815385$

United States Census Bureau. (2000b). Hispanic or Latino origin for the United States, regions, divisions, states, and for Puerto Rico: 2000 (Publication No. PHC-T-10). Retrieved January 5, 2003, from http://landview.census.gov/population/cen2000/phc-t10/tab01-06.pdf

United States Census Bureau. (2000c). Population, housing units, area, and density (geographies ranked by total population): 2000. (Publication No. GCT-PH1-R). Retrieved September 29, 2002, from http://factfinder.census.gov/servlet/GCTTable?ds_name=D\&geo_id=D\&mt_name=DEC_2000 SF1_U_GCTPH1R_US9S\&_lang=en 
United States Census Bureau. (2002). California quickfacts from the U.S. Census Bureau. Retrieved September 16, 2002, from http://quickfacts.census.gov/qfd/states/06000.html

\author{
$\underline{\text { Author Information }}$ \\ Clark A. Davis, Ph.D. \\ Department of Sociology \\ California State University, Chico \\ $400 \mathrm{~W}$. First St. \\ Chico, CA 95929-0002 \\ E-mail: cadavis@csuchico.edu \\ J. Joshua Brown, M.A. Candidate \\ Department of Social Science and Special Programs \\ California State University, Chico \\ $400 \mathrm{~W}$. First St. \\ Chico, CA 95929-0002 \\ E-mail: jbrown43@mail.csuchico.edu
}

